
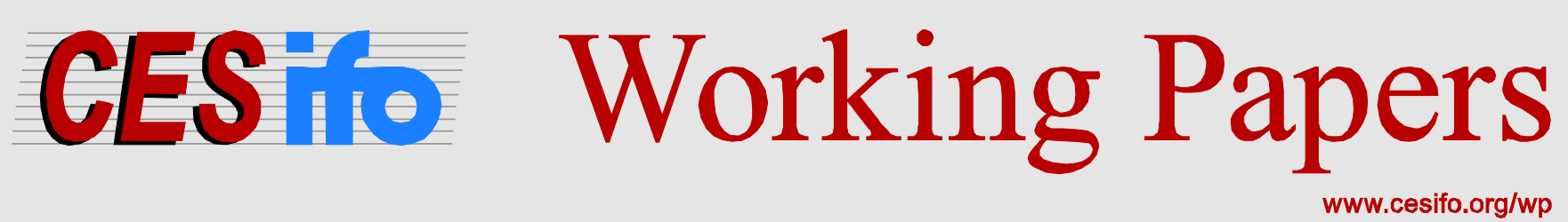

\title{
Behavioral Indifference Curves
}

\author{
John Komlos
}

CESIFO WORKING PAPER NO. 4856

CATEgORY 13: BEHAVIOURAL ECONOMICS

JUNE 2014

An electronic version of the paper may be downloaded

- from the SSRN website:

- from the RePEc website:

- from the CESifo website:

www.SSRN.com

Www.RePEc.org

www.CESifo-group.org/wp

\section{CESifo}




\title{
Behavioral Indifference Curves
}

\begin{abstract}
According to the endowment effect there is some discomfort associated with giving up a good, that is to say, we are willing to give up something only if the price is greater than the price we are willing to pay for it. This implies that the indifference curves should designate a reference point at the current level of consumption. Such indifference maps are kinked at the current level of consumption. The kinks in the curves imply that the utility function is not differentiable everywhere and the budget constraint does not always have a unique tangent with an indifference curve. Thus, price changes may not bring about changes in consumption which may be the reason for the frequent stickiness of prices, wages and interest rates. We also discuss a multiple period example in which the indifference map shifts as the reference point shifts implying that the curves cross over time even though tastes do not change.
\end{abstract}

JEL-Code: A200, B500, D030, D110.

Keywords: behavioral economics, indifference curves, endowment effect, reference state, gain and loss equivalence, stickiness of prices and wages.

\author{
John Komlos \\ University of Munich \\ Germany \\ john.komlos@econhist.vwl.uni-muenchen.de
}

Highlights:

- Standard indifference curves are inconsistent because they do not indicate the prior level of consumption.

- Behavioral indifference curves incorporate a reference point which is the prior level of consumption.

- Behavioral indifference curves with an endowment effect are kinked at the current level of consumption.

- The kink in the indifference curves may account for the stickiness of prices, wages, and interest rates.

- As the reference point moves over time so does the indifference map. 
It is important to update the way we teach indifference curves. The standard depiction is still being taught to millions of students annually, although a crucial inconsistency with its conceptualization was discovered more than three decades ago, namely that it fails to indicate the reference point or the current level of consumption (Knetsch and Sinden, 1984;

Kahneman, Knetsch, and Thaler 1990; Knetsch, Riyanto, and Zong, 2012). According to the conventional indifference curve diagrams when deciding between two goods, say, food and clothing, it is as though we've never consumed them before. Thus, we are assumed to come to the problem in a pristine state, without indicating the amount of the goods in question we consumed in the prior period or are adapted to. However, this is contradictory, because if we have not consumed these items before how are we supposed to know how much utility we should expect from them.

Hence, the customary indifference curve depends on the implicit assumption that choice along indifference curves are reversible. That is, if an individual owns $\mathrm{x}$ and is indifferent between keeping it and trading it for $\mathrm{y}$, then when owning $\mathrm{y}$ the individual should be indifferent about trading it for $\mathrm{x}$. If loss aversion is present, however, this reversibility will no longer hold (Knetsch 1989; Kahneman, Knetsch, and Thaler 1991). Knetsch and Sinden were the first to point out that the standard assumption pertaining to the equivalence of losses and gains is contradicted by the experimental evidence: "the compensation measure of value seems to exceed significantly the willingness to pay measure, which would appear to call into some question... interpretations of indifference curves” (Knetsch and Sinden, 1984).

Thus, the mainstream representation of indifference curves is outdated, inconsistent, and misleading, because it overlooks the ample empirical evidence that current consumption (or current endowment) matters to subsequent consumption decisions as it becomes a 
reference point to which other states of the world are compared (Rabin 2008). The endowment effect implies that there is an excess discomfort associated with giving something up, i.e., in excess of the pleasure associated with acquiring it. Let us suppose that the current level of consumption is $\left(\mathrm{Q}_{\mathrm{x} 1}, \mathrm{Q}_{\mathrm{y} 1}\right)$ (Figure 1). Then point “ $a$ ” becomes the origin of the coordinate system and the relevant reference point for the current period 1 . While recently there has been some discussion about how to define the reference point in various circumstances (Heffetz and List, 2013), in this example it is straightforward, it is simply the current level of consumption at point $a$.

We divide the plane into four quadrants (numbered counter clockwise) with the axis going through the origin at point $a$. In quadrant 1 the reference point is irrelevant as both $\mathrm{x}$ and y are increasing. In this quadrant the standard convex-to-the-origin indifference curve is unchanged. However, $x$ decreases in quadrant 2 while $y$ increases; in quadrant 3 both $\mathrm{x}$ and $\mathrm{y}$ decrease, and in quadrant $4 \mathrm{x}$ increases while y decreases. (All changes are relative to the axis that go through the initial reference point $a$ (Figure 1).

Thus, lowering consumption of $(\mathrm{x})$ below the initial level, $\mathrm{Q}_{\mathrm{x} 1}$, requires a larger amount of a compensating good (y) in order to maintain the same level of utility than the amount of $y$ required to be given up if there were an identical increase in $x$ beyond $\mathrm{Q}_{\mathrm{x} 1}$. In other words, at point $a$ the loss in marginal utility of giving up a unit of $\mathrm{x}$ is larger (in absolute value) than the marginal utility of obtaining a unit of x; i.e., decreasing one's consumption from the current level is more painful than increasing consumption from the current level is beneficial. This is critical, because it implies that the indifference curves are kinked at the axis that go through point $a$, with slopes steeper in quadrant 2 than in quadrant 4, a factor overlooked in conventional treatments of indifference curves. David Just works out the properties of such behavioral indifference maps with straight lines, i.e., with constant marginal rate of substitution (Just 2014, p. 81), while Knetsch et al demonstrate with 
indifference curves the discrepancy of evaluating welfare in the domains of gains and losses (Knetsch, Riyanto, and Zong, 2012).

To demonstrate the impact of the endowment effect on the indifference map with declining marginal rate of substitution (mrs) let us suppose that the standard (mrs) along an indifference map were $\mathrm{m}_{\mathrm{i}}=-\frac{\Delta Y_{i}}{\Delta X_{i}}$, and the endowment effect of $\mathrm{x}$ at a point $\mathrm{i}$ is given by $\varepsilon_{\mathrm{xi}}$ and that of $y$ is given by $\varepsilon_{y i}$ where $\varepsilon>0$ is the extra price (in terms of the other good) required to give up an object above the price for which it would be acquired. Then the mrs of the behavioral indifference curve in quadrant 2 relative to the reference point $a$ is $\mathrm{bm}_{\mathrm{i}}=-\frac{\Delta Y_{i}+\varepsilon_{y i}}{\Delta X_{i}}$, in quadrant 3 is $\mathrm{bm}_{\mathrm{i}}=-\frac{\Delta Y_{i}+\varepsilon_{y i}}{\Delta X_{i+} \varepsilon_{x i}}$, and in quadrant 4 is $\mathrm{bm}_{\mathrm{i}}=-\frac{\Delta Y_{i}}{\Delta X_{i+} \varepsilon_{x i}}$. Hence, in quadrant 2 the slope of the indifference curve is steeper than the standard indifference curve because in order to give up 1 unit of $\mathrm{x}$ one would need a greater amount of $\mathrm{y}$ as compensation on account of the pain of giving up x relative to the level to which one is accustomed. Similarly, in quadrant 4 except in this case the indifference curve is flatter than the standard indifference curve because in this case it is more difficult to give up y. In quadrant 3 the slope of the behavioural indifference curve relative to the standard one is ambiguous depending on the sizes of $\varepsilon_{\mathrm{xi}}$ and $\varepsilon_{\mathrm{yi}}$; the curve is drawn in this quadrant in such a way so that the endowment effects cancel each other and the standard indifference curve obtains.

The implication is that there is a kink in the behavioral indifference curves as they cross the axis from one quadrant to another. This implies that the utility function is not differentiable everywhere and that preferences are not homothetic. Moreover, budget lines cannot be tangent to the indifference curve along the axis that divides the plane into four quadrants. For instance, budget lines 1 and 2 in Figure 2 show that changes in price will not bring about any change in the consumption bundle at point $a$, contrary to conventional 
analysis. This may well explain the oft found stickiness in adjustment to changes in wages, prices, and interest rates (Anderson 1998; Carlton, 1986; Ausubel, 1991).

Furthermore, let us suppose that in period 1 the actual budget line 3 is tangent to the indifference curve at $b$ in quadrant 4 ( $b$ is not on an axis in period 1$)$. Thus, Figure 2 shows that with budget constraint 3 the new consumption bundle becomes $\left(\mathrm{Q}_{\mathrm{x} 2}, \mathrm{Q}_{\mathrm{y} 2}\right)$ at point $b$. Once choosing to consume at point $b$ in period 1 , however, the origin of the new axis of the behavioral indifference map shifts to $b$ and, in turn, that becomes the new reference point in period 2. This implies that the two sets of indifference maps cross over time even if the taste of the consumer does not change over time. ${ }^{1}$

Moreover, the new indifference map of period 2 is superimposed on the previous one of period 1 (Figure 3). However, the budget constraint, which was tangent to the old indifference curve at $b$ is no longer tangent to the new indifference curve at $b$ (Figure 4). Therefore, the tangency with the new set of indifference curves will be elsewhere implying that consumption will change in period 2 even if prices, income, or taste remain unchanged. Thus, the consumption bundle can change even if there is no fundamental change in either the economy or in the consumer's preferences. In other words, the adjustment to the new budget constraint occurs in two steps: the first step uses the initial reference point in order to choose the optimal bundle and having made that choice the reference point also shifts implying that the whole indifference curve shifts. This, in turn, displaces the optimal consumption bundle once again to c even if there are no other changes in the relevant parameters.

In sum, behavioral indifference curves are relative to a reference point. The endowment effect implies that people are willing to give up an object only at a higher price than the price at which they are willing to buy it, i.e., it is psychologically more difficult to give up an object than to acquire it. This changes the shape and properties of the indifference map that has far-reaching implications and not only in the classrooms but also in 
applied areas such as the evaluation of welfare states and stickiness of economic variables such as wages, prices, and interest rates (Knetsch, Riyanto, and Zong, 2012). This salient issue ought no longer be ignored and needs a much wider research agenda than hitherto allotted to it at the margins of the discipline.

Even at this stage it is important to incorporate the behavioral indifference curves into the curriculum and stop teaching outdated concepts. If you think that behavioral indifference curves would be too complicated for beginners then I would urge you not to teach the conventional ones until the students are ready for the current version because one should not mislead students by teaching inappropriate concepts. If the straight-talking Nobel-prize winning physicist Richard Feynman (1918-88) were still with us he would concur with this view; in his famous 1974 commencement address at the California Institute of Technology, he beseeched the graduating class to practice scientific integrity, utter honesty, and to lean over backwards so as not to fool ourselves [and of course others] (Feynman 1985). I believe that the same is true for us: teachers of economics: it is time to start leaning over backwards and to stop teaching the standard indifference curves. 
Figure 1. Behavioral indifference curves in Period 1 showing initial endowment

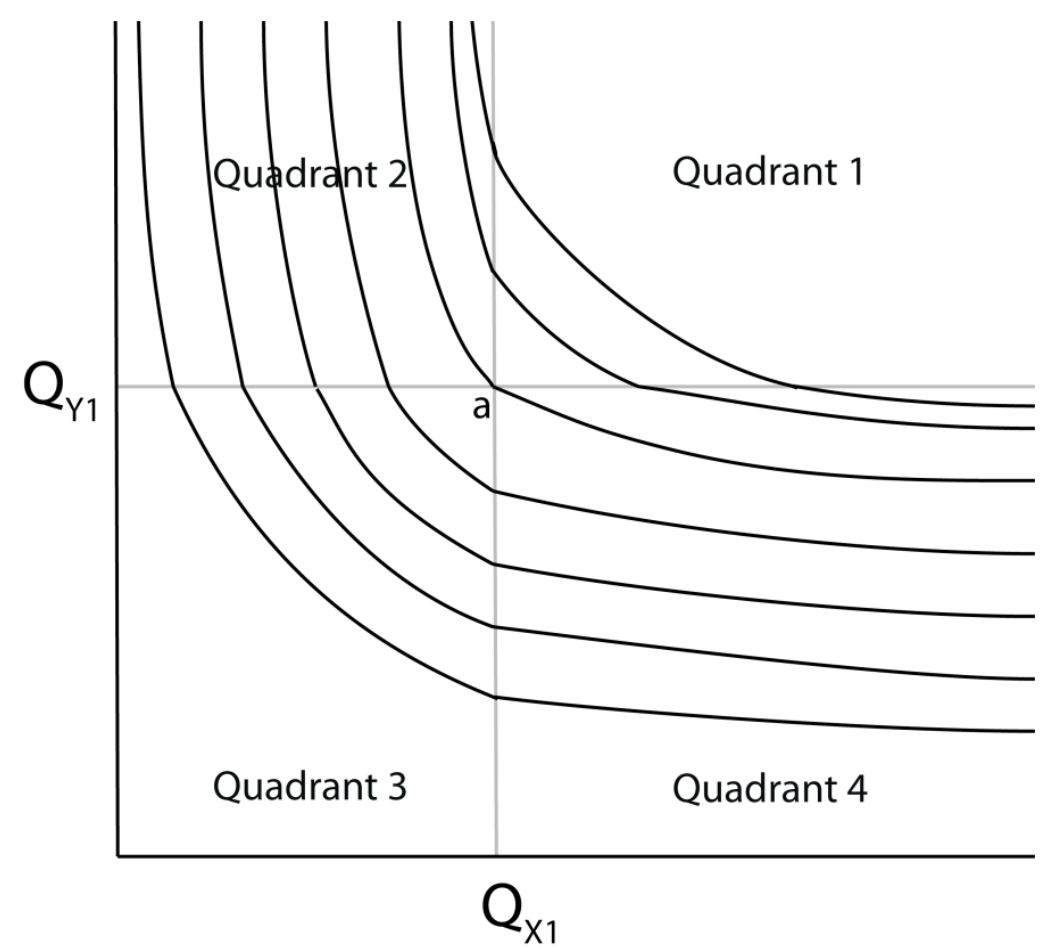


Figure 2. Behavioral indifference curves in Period 1 with several budget constraints

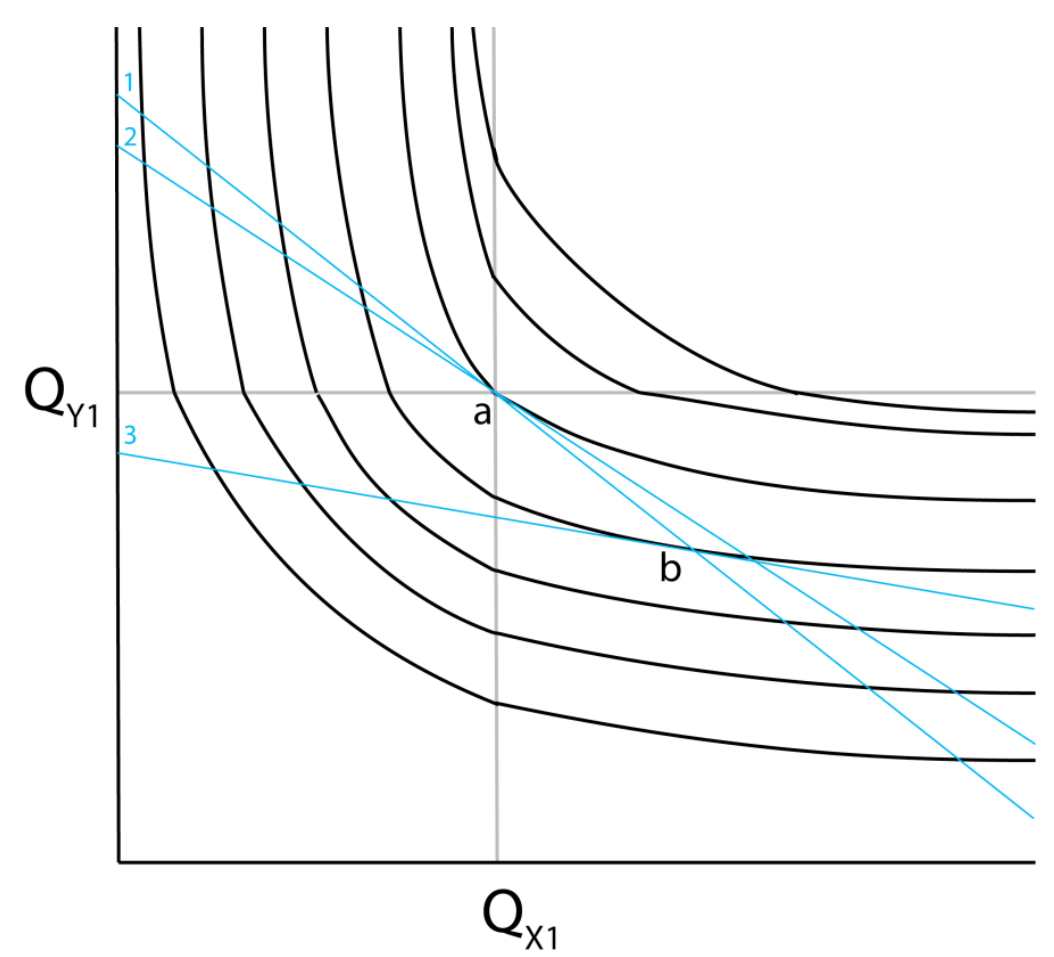


Figure 3. In period 2 behavioral indifference curves shift the origin from a to new reference point at b

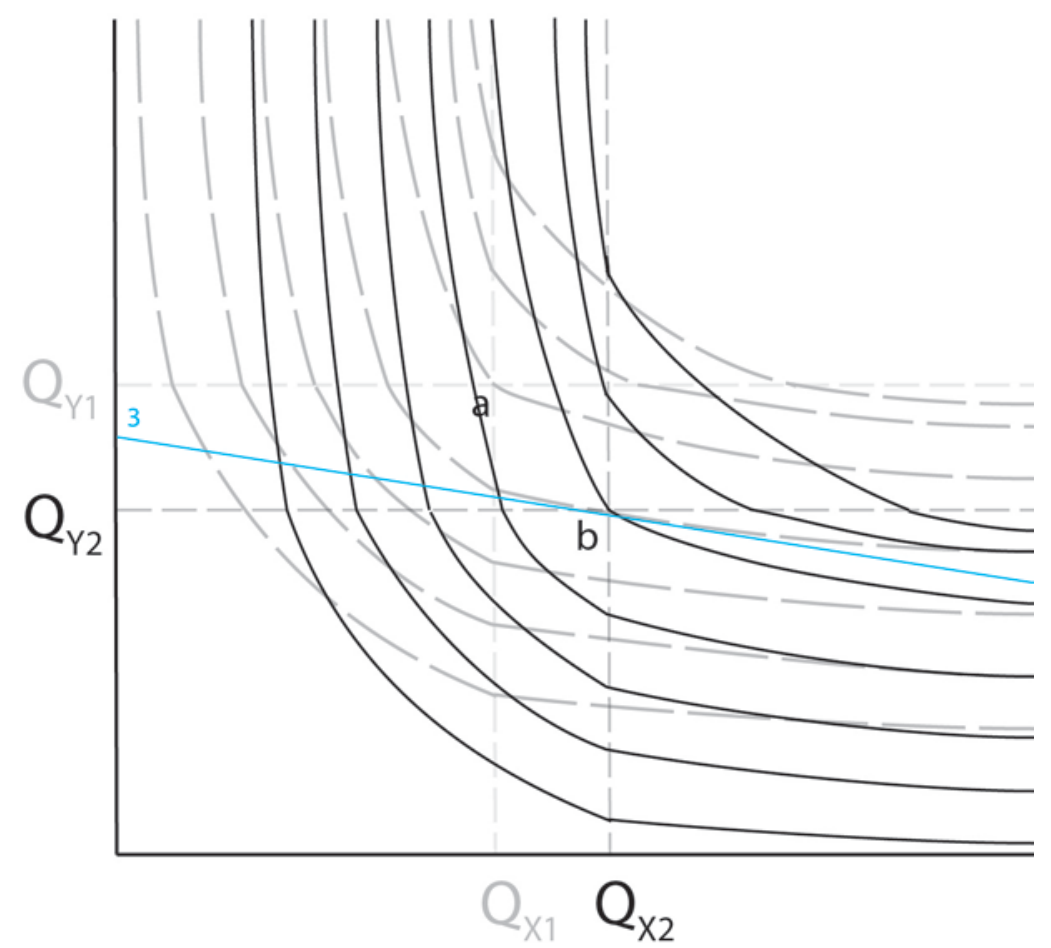


Figure 4. In period 2 consumption changes to point c even if there is no change in taste or the budget constraint.

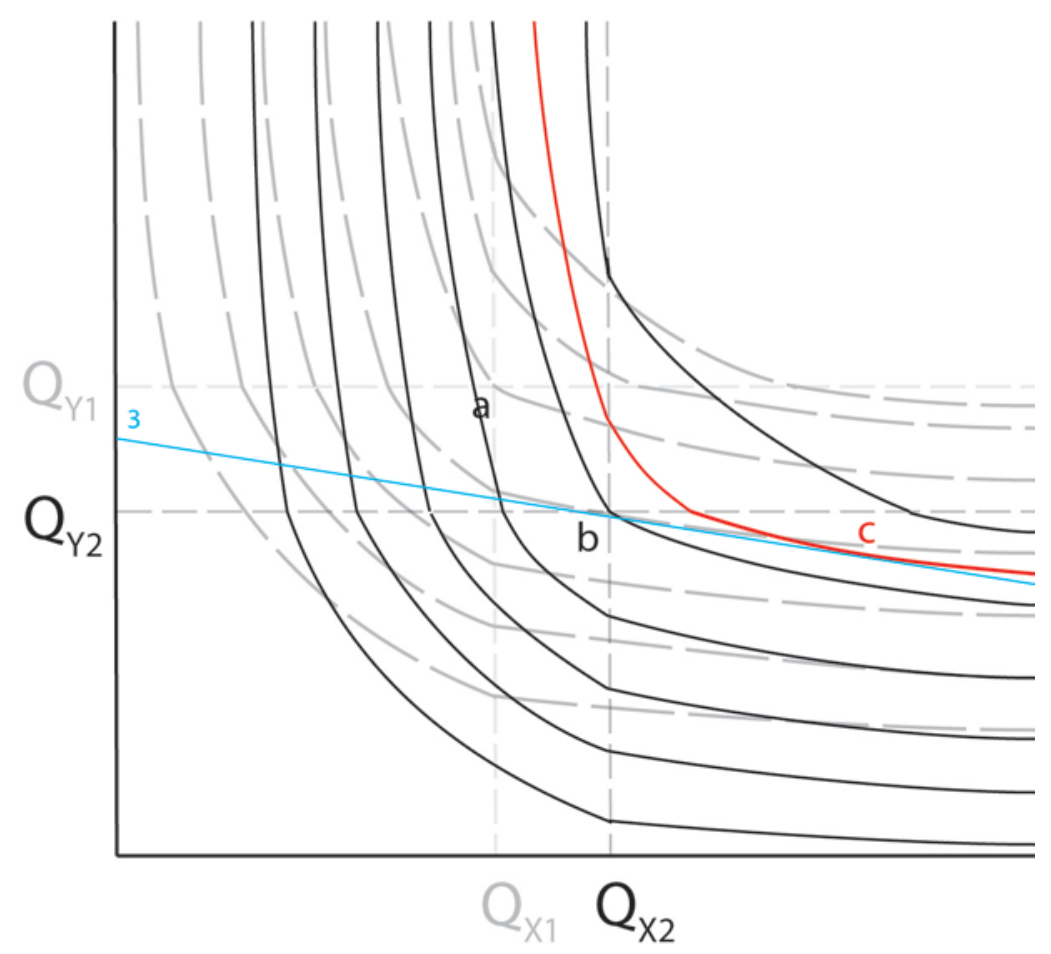




\section{References}

Andersen, T.M., 1998. Persistence in sticky price models. European Economic

Review 42, 593-603.

Ausubel, L., 1991. The failure of competition in the credit card market. American Economic

Review 81, 50-81.

Carlton, D.W., 1986. The rigidity of prices. American Economic Review 76, 637-58.

Feynman, R.P., 1985. Cargo Cult Science. In: Feynman, R.P. Leighton, R., Hutchings, E.

(Eds.). Surely You're Joking, Mr. Feynman!. New York: W.W. Norton, 338-46.

Heffetz, O., List, J., 2014. Is the Endowment Effect an Expectations Effect? Journal of the European Economic Association, forthcoming.

Just, D.R., 2014. Introduction to Behavioral Economics. New York: Wiley and Sons.

Kahneman, D., Knetsch, J.L., and Thaler, R.H., 1990. Experimental Tests of the Endowment

Effect and the Coase Theorem. Journal of Political Economy 98, 1325-48. . 1991. Anomalies: The Endowment Effect, Loss Aversion, and Status Quo Bias.

Journal of Economic Perspectives, 5 (1): 193-206.

Knetsch, J.L., 1989. The Endowment Effect and Evidence of Nonreversible Indifference Curves. American Economic Review 79, 1277-84.

Knetsch, J.L., Sinden, J.A., 1984. Willingness to pay and compensation demanded:

Experimental evidence of an unexpected disparity in measures of value, Quarterly Journal of Economics 99, 507-521.

Knetsch, J.L., Riyanto, Y.E., Zong. J., 2012. Gain and Loss Domains and the Choice of Welfare Measure of Positive and Negative Changes. Journal of Benefit-Cost Analysis 3, Article 1.

Rabin, M., Kahneman, D. (born 1934). The New Palgrave Dictionary of Economics. Second Edition. Eds. Steven N. Durlauf and Lawrence E. Blume. Palgrave Macmillan, 2008. The 
New Palgrave Dictionary of Economics Online. Palgrave Macmillan.

http://www.dictionaryofeconomics.com/article?id=pde2008_K000065 (accessed May 26, 2014).

\section{Endnotes}

1 That indifference curves can intersect has been experimentally verified in a different setting (Kahneman, Knetsch, and Thaler, 1991, p. 197). 